\title{
Black Elephant
}

Tug Dumbly

He'd turn up with their kids and a glass of wine. New to the park. Maybe trying to polish the scene of sprogs in dog shit shoes chucking doggy-bag water bombs into something a bit more refined.

One day she turned up with their kids and a shiner. No trip into a cupboard this.

Too exact a coal black pit. But there was no trying to hide it behind shades. She flew it like a pirate flag

over the park, in battered broadside display. She didn't say and we didn't ask about what was so achingly stamped. She just invited our silent surmise of the black elephant.

Who's sorry now? her bruised skull screamed. She'd screw a penance from him to make mincemeat of his puny hook-she'd barbeque his good name slow, on the spitting rotisserie of public shame. 
I never liked the woman. For all the usual piss-poor reasons. She was pale and unsmiling, unreadable, aloof.

Plus her son nearly blinded mine with a kebab skewer.

The jab missed his eye by an inch.

They were only five, just kids trying to kill each other in the usual way.

Could happen to anyone. Not her fault. Though still we suckle blame.

He made the kid make cookies and bring them to our door as an act of contrition.

l'll grant him that. It was a nice little lesson in actions and consequences and the need for amends

a lesson he himself was now learning again. I admired her guts turning up like that, out of the blue with that shining black. He wasn't back in the park for a while, and then without his glass of wine

swallowed by the badge of her brutal pride. 